\title{
Improving Polymer Science Asynchronous Online Lecture Contents For Students' Engagement
}

\author{
Charles Darko \\ Department of Materials, The University of Manchester, Manchester United \\ Kingdom
}

Doi:10.19044/esj.2021.v17n25p95

Submitted: 17 May 2021

Copyright 2021 Author(s)

Accepted: 01 July 2021

Under Creative Commons BY-NC-ND

Published: 31 July 2021

4.0 OPEN ACCESS

Cite As:

Darko C. (2021). Improving Polymer Science Asynchronous Online Lecture Contents For Students’ Engagement. European Scientific Journal, ESJ, 17(25), 95.

https://doi.org/10.19044/esj.2021.v17n25p95

\section{Abstract}

Asynchronous online delivering methods have been found to promote excellent engagement among students but the impact in the teaching of polymer science courses have not been investigated. This work discussed and reflected critically on the ways of improving polymer science lecture contents in asynchronous videos that can enhance and motivate students' learning. Six polymer science topic combinations in the forms of structure characterisation, structure- processing, structure - properties, characterization - processing, properties - characterization and properties - processing were established. Lecture slides based on these combinations were created and 106 students were tasked to read and rate them on computer screens. First, second and third-year undergraduate material science and engineering students rated the combinations based on stimulation, motivation and effectiveness. Results show that there was no strong preferred choice(s) from the first years but the second year students appeared to favour the structure-property combination while third-year students preferred the structural-property-processing lecture contents. Using the cognitive learning theory and the redundant effect, the third-year students were described to have processed the information received and classified some redundant while the first-year students might have accumulated all information into their limited working memory without redundancy since they lack prior knowledge of the polymer science topics. 
These reasons coupled with basic students' computer skills were attributed to influence their judgements during the rating.

Keywords: Student Engagement; Asynchronous; Polymer Science; Cognitive Learning; Redundancy Effect

\section{Introduction}

Presently, teaching and learning are being done remotely because of the COVID pandemic. The major issue for polymer science lecturers is how to present the polymer science contents that motivates and engages students. This is a very difficult task since most of the polymer topics such as the structures, characterization, physics and processing need to be addressed when preparing the asynchronous video contents. The focus of the work is a critical discussion and reflection on the ways of improving the polymer science lecture contents in asynchronous recorded videos that can enhance the motivation and self-study efficacies among material science students. Even though a combination of asynchronous and synchronous teaching methods was found to be effective for content delivery and active learning within an organic chemistry class (Sunasee, 2020), there are many challenges associated with asynchronous teaching and learning methods (Aloni \& Harrington, 2018; de Lima et al., 2019; Raes et al., 2020; Zydney et al., 2020; Gal \& IsraelFishelson, 2020; Öztürk, 2021). Previous findings revealed lecture content issues that are associated with instructional strategies, considerations and integration of multimedia in online content development which affects students' expectations, readiness, identity, and participation (Kebritchi et al., 2017).

Online learning has emerged in recent times because of the global pandemic and most institutions have adopted the blended learning approaches (Stein \& Graham, 2020; Walmsley-Smith, et al, 2019). Within the blended learning approach, instructions done remotely are mostly performed by synchronous (Butz et al., 2015; Blau et al., 2017; Raes et al., 2020; Zydney et al., 2020) and asynchronous (Brady \& Pradhan, 2020; Rovai, 2000) teaching methods. The synchronous teaching method deals with an interaction between the instructors and students that occurs at the same time but online (Rasmussen, 2003) whereas asynchronous methods rely on recorded lecture videos and electronic readable materials organized for students to use at their own will, pace and time remotely (Evans, et al., 2020).

Most of the studies surrounding asynchronous instruction methods have been focused on online discussion forums and their effectiveness in improving students' learning efficacies (Biesenbach-Lucas, 2003; Jorgensen, 2003; Green et al., 2014; Pinto-Llorente, et al., 2017; Koszalka et al., 2020). Recently, asynchronous online discussions were found to promote excellent 
engagement in discussions of content-related materials and results showed evidence of deep learning among students (Koszalka et al., 2020). In that study, Koszalka and colleagues (2020) investigated students' participation, interaction, and levels of learning in the asynchronous online discussions and students were tasked to evaluate and synthesize information during the collaboration that builds knowledge. In the past, studies have also indicated that asynchronous online discussion forums within a blended learning model can be an effective tool for improving students' learning outcomes and also offered benefits of greater social interaction among peers (Biesenbach-Lucas, 2003; Green et al., 2014).

As stated earlier, despite the benefits of using asynchronous teaching methods, there are issues and challenges associated with the implementation. Recent studies revealed some technological and pedagogical issues associated with the creation of quality learning materials within the asynchronous methods (Raes et al., 2020; Zydney et al., 2020). Technologically, even though asynchronous tools are perceived as instructional resources that allow easy access to materials of the subject according to their necessities beyond the classroom (Pinto-Llorente, et al., 2017), it was observed that the implemented ICT tools do not automatically facilitate students' adoption of active learning strategies in online discussions and that care must be taken to fully understand the students' total engagement and contributions with such tools (Wang, 2010). In an attempt to document and understand task related postings in asynchronous computer conferencing that foster knowledge construction, Hong and Lee (2008) noted that students were active in knowledge construction but limited to seeking and giving opinions among peers and knowledge telling. It was proposed that the e-learning facilitator could model some dynamics of sharing information and transforming the knowledge acquired.

Examples of the pedagogical issues surrounding asynchronous online discussions are the challenges of not focusing discussions on the lecture contents but unrelated topics. Another issue is the surface discussions that occur among students without deep level thinking that can move them beyond fact recollection from the textbook (Aloni \& Harrington, 2018; de Lima et al., 2019). These may affect asynchronous online discussions and may not contribute to students' learning but simply keep students busy in their online course. Other studies have also shown that when students are confused and do not know the purpose and the value of the asynchronous online discussions, they get demotivated and do not want to participate (Balaji \& Chakrabarti, 2010; Kim, 2013; Lee, 2013; Yeh \& Van Buskirk, 2005). Similarly, de Lima and colleagues (2019) in a quest to identify the benefits and difficulties of using online discussion forums from the instructors' point of view, noted that when there are challenges or difficulties with the structure of the online 
forums, they hinder students' motivations. However, when the asynchronous learning structures and content are properly managed, they can offer greater benefits to the students (Jorgensen, 2003).

\section{The teaching of polymer science}

Polymer science is a relevant subject of science taught in many material science and engineering programs (Billmeyer, 1984; Gowariker et al., 1986; Sperling, 2005). At most higher education institutions, students are normally introduced to polymers in the early part of their undergraduate programs and can specialize towards the end of their studies. Billmeyer (1984) introduced all areas of polymer science in detail and divided polymer science into six chapters covering an introduction, synthesis, characterization, structure and properties, properties of commercial polymers, and polymer processing (Billmeyer, 1984). Moreover, it was noted that a modern and engaging polymer science curriculum must be constructed for all students with different conceptual knowledge by combining traditional elements of polymer science and contemporary polymer sciences to promote a lively and diverse teaching practice (Stenzel \&Barner-Kowollik, 2006). By combining different aspects of polymer science, students' engagement and interest can be maximized.

Furthermore, the polymer science curriculum must be built on solid principles. An understanding of macromolecules must be established by relating the physical and mechanical properties of polymeric materials to a molecular structure that give students a strong polymeric foundation (Jefferson \& Phillips, 1999). As one of the challenges in polymer science is the lack of bridging the microstructural characteristic of polymers with their material characteristics, it is prudent to combine various principles that are appreciable by students (Doi, 2003). It is therefore essential to find possible lecture combinations that can build a strong foundation for the polymer scientist.

\section{Reading information from the computer screen}

Excessive participation in asynchronous online discussions may occasionally inhibit students' learning by drawing time away from other important course works and instructors must monitor online discussions they initiate to ensure better use of student's time (Wolff \& Dosdall, 2010). To aid effective online discussions and reduce student's information search times on screens, there must be implemented strategies that ensure excellent content quality. Based on cognitive theories, part of the reason for lack of retention is hypothesized to be the user's inability to form a mental picture of the information presented via a computer screen (Chalmers, 2003) although tablets may pose technological hindrance during information capturing 
because tablets might require the use of additional mental resources that hinder performances (Debue et al., 2020).

Figure 1 shows a schematic diagram of the way the eye visualize information on the screen. When focused light is projected onto the retina, nerve signals are sent through the back of the eye to the optic nerve by the retina (Larissa, 2019). The retina is made up of millions of light receptors known as rods and cones that detect visible light and convey information to the brain. The brain interprets the information as visual images. Gazing and eye movement in front of the computer can predict user intentions (Biedert et al., 2010). It was noted that gazing normally prompts the user's attention and can be related to the user's reading behaviour while gazing coupled with the user's eye movements can inform cognitive processes within the brain (Biedert et al., 2010). This is because our attentional orienting system quickly and automatically prioritizes salient visual events (Carrasco \& Hanning, 2020).

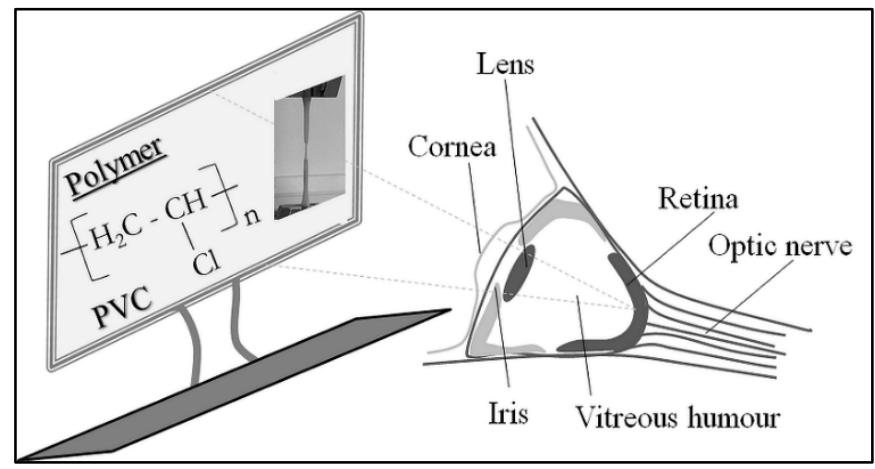

Figure 1. An image capturing from a computer screen

Furthermore, factors that affect readability on computer screens are the features of the characters, the formatted screens, the contrast and colour of the characters, the background, and the dynamic aspects of the screens (Mills \& Weldon, 1987). In a study to find possible web design issues, information search times from the web using desktop monitor (full-sized) and a palm handheld interface (small-screen) were recorded but the data spread was found to be too high (Kim \& Albers, 2001). Kim and Albers (2001) concluded that designing information differently will not help beyond a certain point for some people but rather user motivation for finding the information, different types of information, and user knowledge of the types of information are key factors for consideration. Moreover, reading to comprehend and learn are done without the concern for reading speed but on content quality (Dillon, 1992). 


\section{Cognitive processes}

In the cognitive learning theory, learning is described as the creation of knowledge and conceptual development and can include the storing of knowledge in the brain and how it is used (Satzinger, 1998; Bartlett \& Bartlett, 1995; Bernstein, 2018). Piaget was described to propose that learning is the result of forming new schemas (i.e. a pattern of thought) and building upon previous schemas (Chalmers, 2003). Piaget proposed that during learning, there is an organization of schemas and adaptation of schemas. Information retention is better when learners create the knowledge themselves by absorbing and readjusting previous schemas (McNamara, 1995). Moreover, the cognitive load theory suggests that the less cognitive load a learner carries, the easier learning should be because high cognitive load brings limitations within the working memory that might have an adverse effect on learning (Sweller \& Chandler, 1994; Yeung, 1999).

\section{Computer screen design}

A good screen design enables spontaneous processing of information, reduces cognitive load and improve students' learning activities (Nichols, 2016). The cognitive load demanded by on-screen reading is greater than that for print because readers have to engage with additional navigational activity such as scrolling (DeStefano \& LeFevre, 2007; Lauterman \& Ackerman, 2014; Mangen, 2008; Mangen et al., 2013; Margolin et al., 2013; Wästlund, Norlander, \& Archer, 2008; Wästlund et al., 2005). Hence, poorly designed computer screens hinder communication (Heines, 1984).

\section{Education level and computer usage}

The novice learner because of the education level might lack the basic computer skills to scan through the screen and this may impact their ability to absorb information. As discussed earlier (figure 1), if the required information lands on the retina, they are transported to the brain by the optical nerve (Larissa, 2019) and the brain interprets the information and supports the cognitive learning process (Biedert et al., 2010) before prioritizing the salient visual events (Carrasco \& Hanning, 2020). It is worth mentioning that the required computer skill can also affect the mood of scanning computer screens efficiently (Rozell \& Gardner, 2000). In the past, researchers have concluded that positive moods predispose people towards using computers, while negative moods contribute to computer avoidance (Dambrot et al., 1988, Mitra, 1998).

\section{Purpose of this study}

This work investigates the effects of varying lecture contents, within the polymer science courses, that are displayed in asynchronous videos on 
students' motivation and stimulation. It is worth mentioning that a study was performed on the utilization of an eye-tracking technique to examine the relationships between students' visual behaviours and their cognitive structures, as well as their information processing modes (Wang et al., 2020). In that study, Wang and the colleagues (Wang et al., 2020) suggested that instructors must provide more varied and integrated information for students' reading tasks to enhance and enrich students' cognitive structures. Employing the recommendation from Wang and colleagues (Wang et al., 2020), this work focused on varying the polymer science lecture contents that can motivate and enhance students learning without focusing on the eye-tracking studies.

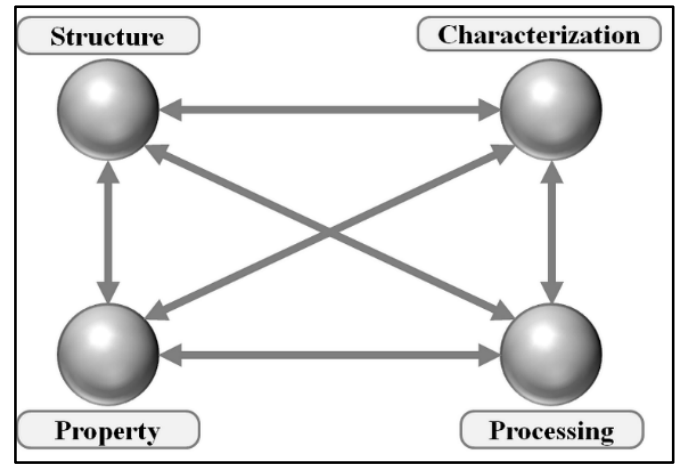

Figure 2. Overview of topic combinations used in testing student's satisfaction when viewing polymer science content online

Table

Table 1. Summary of responses from all student groups

\begin{tabular}{|c|c|c|c|c|c|}
\hline Combinations & $\begin{array}{l}\text { Year } \\
\text { group }\end{array}$ & Stimulation & $\begin{array}{l}\text { Effective } \\
\text { learning }\end{array}$ & Clear & Understanding \\
\hline \multirow{3}{*}{$\begin{array}{l}\text { Structure } \\
\text { Property }\end{array}$} & 1 & 22 & 35 & 31 & 28 \\
\hline & 2 & 16 & 17 & 19 & 18 \\
\hline & 3 & 12 & 15 & 16 & 13 \\
\hline \multirow{3}{*}{$\begin{array}{l}\text { Structure - } \\
\text { Characterization }\end{array}$} & 1 & 27 & 29 & 37 & 25 \\
\hline & 2 & 14 & 9 & 17 & 12 \\
\hline & 3 & 8 & 9 & 14 & 10 \\
\hline \multirow{3}{*}{$\begin{array}{l}\text { Structure } \\
\text { Processing }\end{array}$} & 1 & 27 & 26 & 31 & 28 \\
\hline & 2 & 14 & 13 & 21 & 17 \\
\hline & 3 & 11 & 13 & 16 & 7 \\
\hline \multirow{3}{*}{$\begin{array}{l}\text { Characterization } \\
\text { - Processing }\end{array}$} & 1 & 25 & 26 & 27 & 21 \\
\hline & 2 & 13 & 12 & 18 & 14 \\
\hline & 3 & 8 & 7 & 11 & 8 \\
\hline \multirow{3}{*}{$\begin{array}{l}\text { Property - } \\
\text { Characterization }\end{array}$} & 1 & 25 & 28 & 34 & 27 \\
\hline & 2 & 13 & 13 & 18 & 14 \\
\hline & 3 & 8 & 7 & 12 & 13 \\
\hline \multirow{3}{*}{$\begin{array}{l}\text { Property } \\
\text { Processing }\end{array}$} & 1 & 23 & 26 & 31 & 30 \\
\hline & 2 & 14 & 13 & 17 & 18 \\
\hline & 3 & 13 & 10 & 10 & 12 \\
\hline
\end{tabular}




\section{Methodology}

In the polymer science lecture programs, the four key topics are the structure, property, characterization and processing. Two topic pairings from these essential polymer topics were created to motivate and stimulate students' remote screen reading. Lecture slides were created using combinations such as structure - characterisation (appendix A, figure 4), structure- processing (appendix A, fig. 1), structure - properties (appendix A, fig. 5), characterization - processing (appendix A, fig. 6), properties characterization (appendix A, fig. 3) and properties - processing (appendix A, fig. 2) as depicted in figure 2. In the combinations, randomly selected images or information from one topic were compared with those from the other topic and were designed on the same screen page (see appendix). Two screen pages, filled with different information or images, were developed for each combination to allow consistency. The established lecture slides were placed on several computer screens to demonstrate asynchronous learning activity and undergraduate first, second and third-year students were tasked to review the established contents and give their feedback. Students spent 10 minutes on each combination and provided feedbacks on paper copies provided (see example copies in the appendix). The paper copies were provided for collecting students' feedback only. A total of hundred and six (106) student feedbacks were collected comprising forty-nine (49) first-year, thirty (30) second-year and twenty-seven (27) third-year students. Students were given the choice to agree, disagree or remain neutral and ratings were obtained based on the number of agreement received for each combination. Ethical approval for this research was granted before getting the responses from the students.

\section{Results}

Table 1 shows the overall feedback received and the information represents the number of responses from students who agree that the combinations stimulate interest, provide effective learning, show a clear structure and promote good understanding.

\section{Interest stimulation}

From the responses (figure 3), it was clear that there were no significant differences in the agreement with all the combinations from the first-year students even though the structure-property combination appears to dip slightly. Similarly, the second-year students gave the same response of liking all combinations but appeared to favour the structure-property combinations. However, year three students rated the structure-property and property-processing higher than the rest. For year three students, the structureprocessing also appeared to overlap the structure-property responses and that 
demonstrates that the year three students favour the structural contents of the polymer science to stimulate their interest.

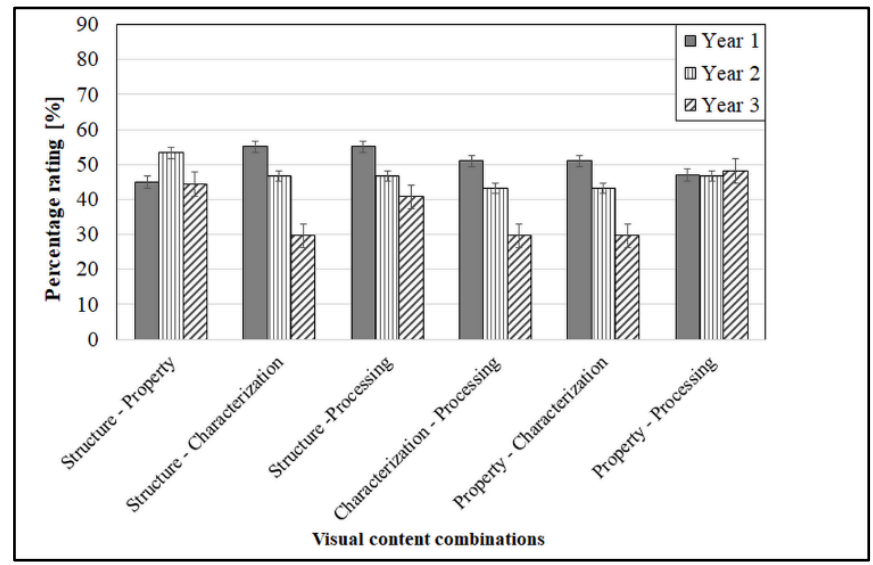

Figure 3. Students' feedback on combinations that stimulates their interest expressed in percentages

\section{Effective learning}

It was interesting to see the structure-property combination rated higher by the first-year students but they gave an equal rating to the rest (figure 4). It can be interpreted as recognizing and learning something new. The second-year students also rated the structure-property higher but gave a very low rating for the structure-characterization combination while the rest received the same rating. The third-year students, on the other hand, gave higher ratings for structure-property and the structure processing combinations but rated the rest lower. The results on the effective learning can be compared to that on the stimulation such that the year three students can be associated with the structural-property-processing contents of the polymer science to motivate, stimulate and enhance their learning.

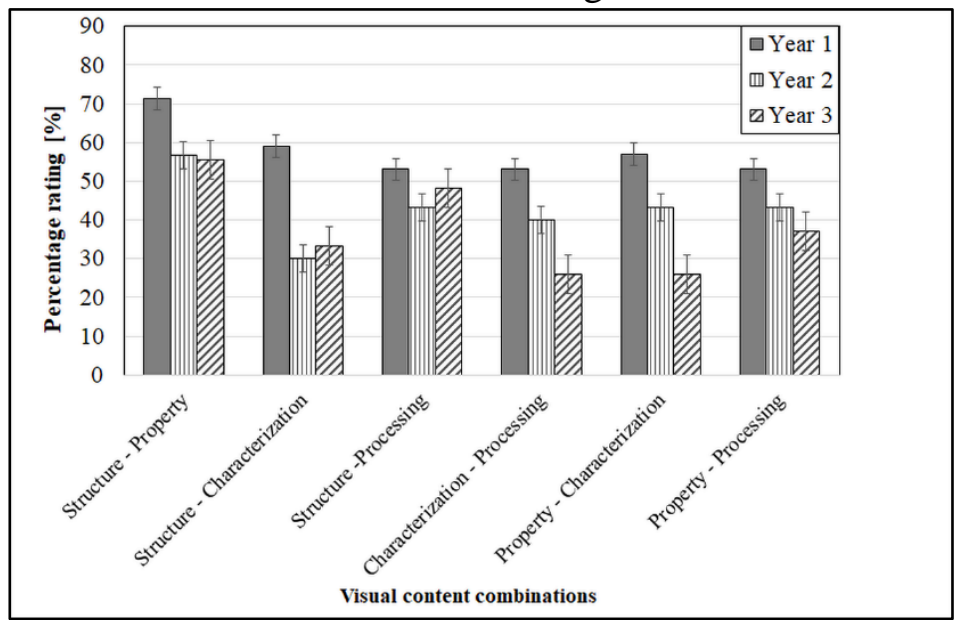

Figure 4. Students' feedback on effective learning expressed in percentages 


\section{Students' understanding}

From figure 5, responses from first-year students indicated similar ratings for all combinations although the characterization-processing showed a lower rating. The second-year students rated the structure-property, structure-processing and property-processing higher than the rest. At this point, the second-year students can also be declared to favour the structureproperty combination to stimulate, motivate and enhance their learning. It is also fascinating to see the structure-property, property-characterization and property-processing combinations to be rated higher by the third year students because that confirms the assertion made in the previous section that the third years favour the structural-property-processing contents to motivate, stimulate and promote effective learning.

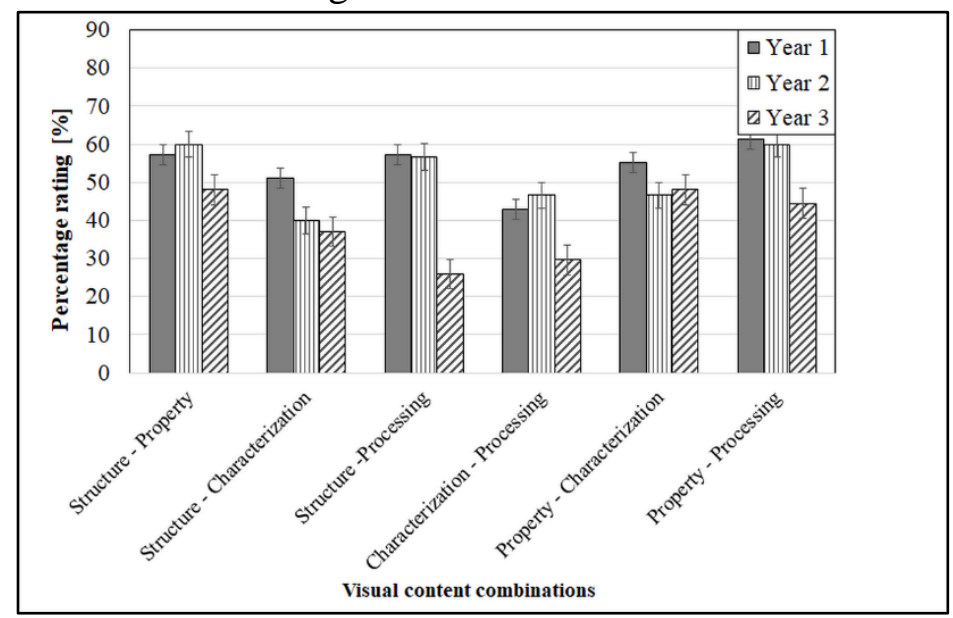

Figure 5. Students' feedback on the understanding obtained from the combinations expressed in percentages

\section{Discussions}

It was observed that the students have different motivations, stimulations and content understandings when reading polymer science information from the computer screens in asynchronous methods. From table 1 , it was fascinating to see the third-year students rating the structure-property and the structure-processing combinations higher than the rest. Looking at figure 6, it can be summarized that the first-year students showed no distinct preference for their choices but the second year students appeared to favour the structure-property combination while third-year students preferred the structural-property-processing lecture contents. For the first-year students, most of them might be new to the polymer topics and will appreciate any combination because they might be curious to learn something new. For the second year students, while some students might still be eager to learn something new, others might have wanted to know detailed structure-property 
contents after receiving an introduction lecture during their first years. For the third year students, it was normal to see their zeal for the structural-propertyprocessing lecture contents simply because they might be thinking of their future careers and how they might link polymer structures with the property as well as the processing.

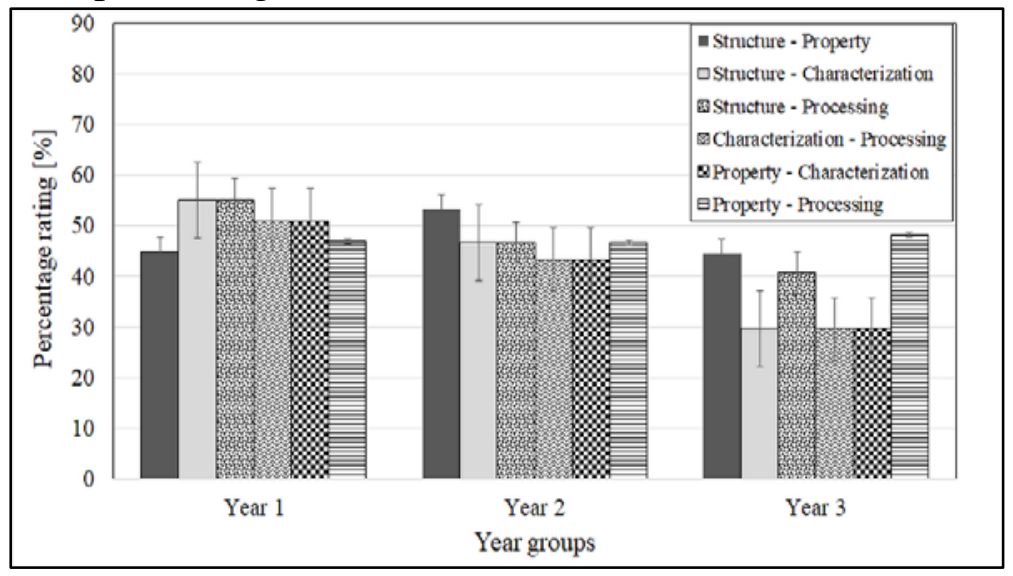

Figure 6. Responses from all year group showing students' satisfaction of the combinations visualized on the screen expressed in percentages

This work has critically discussed and reflected on the strategies of improving polymer science lecture contents in asynchronous recorded videos that enhance and motivate students' learning since online learning has emerged in this global pandemic era. Even though asynchronous methods were found to promote excellent engagement and deep learning among students (Koszalka et al., 2020), the impact on the teaching of polymer sciences has not been studied.

In this study, during the readings from the computer screens, there must have been a cognitive organization to recognize something new, classify information and store them in the brain before learning takes place. The clarity of the images on the screens might have reduced their cognitive load and might have influenced their knowledge acquisition for those combinations. The relationship between the image clarity and perceived cognitive load that influences stimulation and motivation can be extended to the second years who also appeared to slight rate the structure-property images as being clear. The first-year students, however, appeared to rate the structurecharacterization and property-characterization higher in terms of clarity and that shows a slight difference from their previous responses. Some of them might have favoured those combinations based on their abilities to absorb the new information from the screens.

On another angle, most third-year students have had thorough introductory polymer science lectures on polymer materials, molecular 
engineering, manufacturing of monomers, polymerization, physical properties of polymers, etc. (OpenLearn, 2020). Their experiences on the subject must have influenced their decision during the exercise because of the redundancy effect where redundant information is eliminated to enhance learning (Yeung, 1999; Jin, 2012). The cognitive load theory explains that working memory has a limited capacity to handle more information at a time (Sweller \& Chandler, 1994; Yeung, 1999). It means that freeing some information using the redundancy effect improves the cognitive process for effective learning. The third-year students might have incorporated all new information from all combinations into their schemas, processed them and classified some redundant. They could then process and rely on the structure-propertyprocessing to enhance their learning. They may have compared the new information with their previous schemas before their decisions were made. On the other hand, most of the first-year students, new to most of the polymer science contents, might have accumulated all information and might have processed all of them without making some redundant before their judgements. Hence, the lack of significant differences in their responses. Also, it is worth noting that indistinct information for new students who require additional explanatory material may be comprehensible on the part of the third-year students because of their experience (Yeung et al. 1997). The mixed responses from the second-year students can be attributed to emotions between the first and the third years such that while some of their students might prioritized information, others might absorb it all because they lack prior knowledge.

Basic computer skills required when scanning through the computer screen was described to influence the students' decisions. The third-year students who have had several years of experience using the computer or laptop to obtain information or submit course works might have the skills to do careful analysis and selections of salient information than the first-year students who are new to university teaching. The third-year students' retinas' (figure 1) might have been trained to scan and accumulate salient information. The information acquisition, processing and decision-making behaviour of the second-year students were described to be between the first and the third years. The first-year students who are new to the university teaching, without much computer screen reading skills to capture important information, might favour most of the combinations without careful judgements.

Implications are that the first-year students might have to process more information for a long period and that might affect their learning and decisions. The learning behaviour of most second-year students as seen from the results can be described as being between the first year and the second-year students. Therefore, it was not surprising to see the second-year students showing a 
preference for the structure-property combination as compared to the structure, property and processing associated with the third years.

This study is important because it demonstrates that polymer science asynchronous videos can be designed to engage and motivate students' for effective learning. It shows that technology has great potential for stimulating learning and for dealing with pedagogical challenges (Raes et al., 2020) as well as enforcing the need to train instructors, responsible for online content developments at higher education institutions, in providing clear and concise online information.

\section{Conclusion}

Based on the students' agreements to each combination, results within the modelled design demonstrate that first-year students show no strong preferences in any asynchronous polymer science teaching resources. While the second-year students favoured the structure-property combination, thirdyear students preferred the structural-property-processing lecture slide of the polymer sciences. The results from this study contribute to the improvements of polymer science online teaching and learning in material science, polymer chemistry or engineering programmes and look forward to the investigations on the gender differences and information types that can influence the results.

\section{References:}

1. Aloni, M., \& Harrington, C. (2018) 'Research based practices for improving the effectiveness of asynchronous online discussion boards', Scholarship of Teaching and Learning in Psychology, vol. 4, no. 4, p. 271. doi: 10.1037/stl0000121

2. Bartlett, F. C., \& Bartlett, F. C. (1995) Remembering: A study in experimental and social psychology, Cambridge University Press.

3. Bernstein, D. (2018) Essentials of psychology, Cengage learning.

4. Biedert, R., Buscher, G., \& Dengel, A. (2010) 'The eyebook-using eye tracking to enhance the reading experience', Informatik-Spektrum, vol. 33, no. 3, pp. 272-281. doi: 10.1007/s00287-009-0381-2

5. Biesenbach-Lucas, S. (2003) 'Asynchronous discussion groups in teacher training classes: Perceptions of native and non-native students', Journal of Asynchronous Learning Networks, vol. 7, no. 3, pp. 24-46.

6. Billmeyer, F. W. (1984) Textbook of polymer science, John Wiley \& Sons.

7. Blau, I., Weiser, O., \& Eshet-Alkalai, Y. (2017) 'How do medium naturalness and personality traits shape academic achievement and perceived learning? An experimental study of face-to-face and 
synchronous e-learning', Research in Learning Technology, vol. 25. https://doi.org/10.25304/rlt.v25.1974

8. Brady, A. K., \& Pradhan, D. (2020) 'Learning without borders: Asynchronous and Distance Learning in the Age of COVID-19 and Beyond', ATS Scholar, vol. 1, no. 3, pp. 233-242. doi: 10.34197/atsscholar.2020-0046PS

9. Butz, N. T., Stupnisky, R. H., \& Pekrun, R. (2015) 'Students' emotions for achievement and technology use in synchronous hybrid graduate programmes: A control-value approach', Research in Learning Technology, vol. 23. doi: 10.3402/rlt.v23.26097

10. Carrasco, M., \& Hanning, N. M. (2020) 'Visual Perception: Attending beyond the Eyes' Reach', Current Biology, vol. 30, no. 21, pp. R1322R1324. doi: 10.1016/j.cub.2020.08.095

11. Chalmers, P. A. (2003) 'The role of cognitive theory in humancomputer interface', Computers in human behavior, vol. 19, no. 5, pp. 593-607. doi: 10.1016/S0747-5632(02)00086-9

12. Dambrot, F. H., Silling, S. M., \& Zook, A. (1988) 'Psychology of computer use: II. Sex differences in prediction of course grades in a computer language course', Perceptual and Motor Skills, vol. 66, no. 2, pp. 627-636. doi: 10.2466/pms.1988.66.2.627

13. Debue, N., Ou, N., \& van de Leemput, C. (2020) 'An investigation of using a tablet computer for searching on the web and the influence of cognitive load', Tutorials in Quantitative Methods for Psychology, vol. 16, pp. 226-239. doi: 10.20982/tqmp.16.3.p226

14. de Lima, D. P., Gerosa, M. A., Conte, T. U., \& Netto, J. F. D. M. (2019) 'What to expect, and how to improve online discussion forums: the instructors' perspective', Journal of Internet Services and Applications, vol. 10, no. 1, p. 22. doi: 10.1186/s13174-019-0120-0

15. DeStefano, D., \& LeFevre, J.-A. (2007) 'Cognitive load in hypertext reading: A review', Computers in Human Behavior, vol. 23, no. 3, pp. 1616-1641. doi: 10.1016/j.chb.2005.08.012

16. Dillon, A. (1992) 'Reading from paper versus screens: A critical review of the empirical literature', Ergonomics, vol. 35, no. 10, pp. 1297-1326. doi: 10.1080/00140139208967394

17. Doi, M. (2003) 'Challenge in polymer physics', Pure and applied chemistry, vol. 75 , no. 10, pp. 1395-1402. doi: 10.1351/pac200375101395

18. Evans, S., Knight, T., Walker, A., \& Sutherland-Smith, W. (2020) 'Facilitators' teaching and social presence in online asynchronous interprofessional education discussion', Journal of interprofessional care, vol. 34, no. 4, pp. 435-443. doi: $10.1080 / 13561820.2019 .1622517$ 
19. Gal, L., \& Israel-Fishelson, R. 2020 'Enhancing Students Virtual Engagement Using Asynchronous Workshop: COVID-19 Case Study', In EdMedia+ Innovate Learning (pp. 31-36). Association for the Advancement of Computing in Education (AACE).

20. Green, R. A., Farchione, D., Hughes, D. L., \& Chan, S. P. (2014) 'Participation in asynchronous online discussion forums does improve student learning of gross anatomy', Anatomical sciences education, vol. 7, no. 1, pp. 71-76. doi: 10.1002/ase.1376

21. Gowariker, V. R., Viswanathan, N. V., \& Sreedhar, J. (1986) Polymer science. New Age International.

22. Hong, K. S., \& Lee, J. A. C. (2008) 'Postgraduate students' knowledge construction during asynchronous computer conferences in a blended learning environment: A Malaysian experience', Australasian Journal of Educational Technology, vol. 24, no. 1. doi: 10.14742/ajet.1232

23. Heines, J. M. (1984) Screen design strategies for computer-assisted instruction. Digital Press.

24. Jefferson, A., \& Phillips, D. N. (1999) 'Teaching polymer science to third-year undergraduate chemistry students', Journal of chemical education, vol. 76, no. 2, 232. doi: 10.1021/ed076p232

25. Jin P. (2012) 'Redundancy Effect', In Encyclopedia of the Sciences of Learning, Seel N.M. (eds), Springer, Boston, MA. doi: 10.1007/9781-4419-1428-6_200

26. Jorgensen, D. (2003) 'The challenges and benefits of asynchronous learning networks', The Reference Librarian, vol. 37, no. 77, pp. 3-16. doi: 10.1300/J120v37n77_02

27. Kebritchi, M., Lipschuetz, A., \& Santiague, L. (2017) 'Issues and challenges for teaching successful online courses in higher education: A literature review', Journal of Educational Technology Systems, vol. 46, no. 1, pp. 4-29. doi: 10.1177/0047239516661713

28. Kim, L., \& Albers, M. J. (2001) 'Web design issues when searching for information in a small screen display', In Proceedings of the 19th annual international conference on Computer documentation, pp. 193200. doi: 10.1145/501516.501555

29. Koszalka, T. A., Pavlov, Y., \& Wu, Y. (2020) 'The Informed Use of Pre-Work Activities in Collaborative Asynchronous Online Discussions: The Exploration of Idea Exchange, Content Focus, and Deep Learning', Computers \& Education, p. 104067. doi: 10.1016/j.compedu.2020.104067

30. Larissa, H. (2019) 'What Are the Eyes and How Do They Work?', KidsHealth. [online] Available at: 
https://kidshealth.org/en/parents/eyes.html\#: :text=The\%20retina\%2 0(the\%20soft\%2C\%20light,sensitive\%20to\%20light\%20than\%20con es.

31. Lauterman, T., \& Ackerman, R. (2014) 'Overcoming screen inferiority in learning and calibration', Computers in Human Behavior, vol. 35, pp. 455-463. doi: 10.1016/j.chb.2014.02.046

32. Mangen, A., Walgermo, B. R., \& Brønnick, K. (2013) 'Reading linear texts on paper versus computer screen: Effects on reading comprehension', International Journal of Educational Research, vol. 58, pp. 61-68. doi: 10.1016/j.ijer.2012.12.002

33. Margolin, S. J., Driscoll, C., Toland, M. J., \& Kegler, J. L. (2013) 'Ereaders, computer screens, or paper: Does reading comprehension change across media platforms?', Applied Cognitive Psychology, vol. 27, no. 4, pp. 512-519. doi: 10.1002/acp.2930

34. Mills, C. B., \& Weldon, L. J. (1987) 'Reading text from computer screens', ACM Computing Surveys (CSUR), vol. 19, no. 4, pp. 329357. doi: $10.1145 / 45075.46162$

35. Mitra, A. (1998) 'Categories of computer use and their relationships with attitudes toward computers', Journal of Research on computing in Education, vol. 30, no. 3, pp. 281-295.

doi: 10.1080/08886504.1998.10782227

36. McNamara, D. S. (1995) 'Effects of prior knowledge on the generation advantage: Calculators versus calculation to learn simple multiplication', Journal of Educational Psychology, vol. 87, no. 2, 307. doi: 10.1037/0022-0663.87.2.307

37. Nichols, M. (2016) 'Reading and studying on the screen: An overview of literature towards good learning design practice', Journal of Open, Flexible, and Distance Learning, vol. 20, no. 1, pp. 33-43.

38. OpenLearn. (2020) Introduction to polymers, [online] Available at: https://www.open.edu/openlearn/science-maths-

technology/science/chemistry/introduction-polymers/content-section0 ?active-tab $=$ content-tab.

39. Öztürk, M. (2021) 'Asynchronous Online Learning Experiences of Students in Pandemic Process: Facilities, Challenges, Suggestions', Turkish Online Journal of Qualitative Inquiry, vol. 12, no. 2, pp. 173200. doi: $10.17569 /$ tojqi.767378

40. Pinto-Llorente, A. M., Sánchez-Gómez, M. C., García-Peñalvo, F. J., \& Casillas-Martín, S. (2017) 'Students' perceptions and attitudes towards asynchronous technological tools in blended-learning training to improve grammatical competence in English as a second language', Computers in Human Behavior, vol. 72, pp. 632-643.

doi: 10.1016/j.chb.2016.05.071 
41. Raes, A., Detienne, L., Windey, I., \& Depaepe, F. (2020) 'A systematic literature review on synchronous hybrid learning: gaps identified', Learning Environments Research, vol. 23, no. 3, pp. 269-290. doi: 10.1007/s10984-019-09303-z

42. Rasmussen, R. C. (2003) The quantity and quality of human interaction in a synchronous blended learning environment, Brigham Young University, pp. 1-156.

43. Rovai, A. P. (2000) 'Building and sustaining community in asynchronous learning networks', The Internet and higher education, vol. 3, no. 4, pp. 285-297. doi: 10.1016/S1096-7516(01)00037-9

44. Rozell, E. J., \& Gardner III, W. L. (2000) 'Cognitive, motivation, and affective processes associated with computer-related performance: a path analysis. Computers in Human behavior, vol. 16, no. 2, pp. 199222. doi: 10.1016/S0747-5632(99)00054-0

45. Satzinger, J. W. (1998) 'The effects of conceptual consistency on the end user's mental models of multiple applications', Journal of Organizational and End User Computing (JOEUC), vol. 10, no. 3, pp. 3-15.

46. Sperling, L. H. (2005) Introduction to physical polymer science, John Wiley \& Sons.

47. Stein, J., \& Graham, C. R. (2020) Essentials for blended learning: A standards-based guide, Routledge.

48. Stenzel, M. H., \& Barner-Kowollik, C. (2006) 'Polymer science in undergraduate chemical engineering and industrial chemistry curricula: A modular approach', Journal of Chemical Education, vol. 83, no. 10, p. 1521. doi: 10.1021/ed083p1521

49. Sunasee, R. (2020) 'Challenges of Teaching Organic Chemistry during COVID-19 Pandemic at a Primarily Undergraduate Institution', Journal of Chemical Education, vol. 97, no. 9, pp. 3176-3181. doi: 10.1021/acs.jchemed.0c00542

50. Sweller, J., \& Chandler, P. (1994) 'Why some material is difficult to learn’, Cognition and instruction, vol. 12, no. 3, pp. 185-233. doi: 10.1207/s1532690xci1203_1

51. Walmsley-Smith, H., Machin, L., \& Walton, G. (2019) 'The E-Design Assessment Tool: an evidence-informed approach towards a consistent terminology for quantifying online distance learning activities', Research in Learning Technology, vol. 27, pp. 1-14. doi: 10.25304/rlt.v27.2106

52. Wang, M. J. (2010) 'Online collaboration and offline interaction between students using asynchronous tools in blended learning', Australasian Journal of Educational Technology, vol. 26, no. 6. doi: 10.14742/ajet.1045 
53. Wang, C. Y., Tsai, M. J., \& Tsai, C. C. (2020) 'Predicting cognitive structures and information processing modes by eye-tracking when reading controversial reports about socio-scientific issues', Computers in Human Behavior, vol. 112, p. 106471. doi: 10.1016/j.chb.2020.106471

54. Wästlund, E., Norlander, T., \& Archer, T. (2008) 'The effect of page layout on mental workload: A dual-task experiment', Computers in Human Behavior, vol. 24, no. 3, pp. 1229-1245. doi: 10.1016/j.chb.2007.05.001

55. Wästlund, E., Reinikka, H., Norlander, T., \& Archer, T. (2005) 'Effects of VDT and paper presentation on consumption and production of information: Psychological and physiological factors', Computers in Human Behavior, vol. 21, no. 2, pp. 377-394. doi: 10.1016/j.chb.2004.02.007

56. Wolff, B. G., \& Dosdall, M. R. (2010) 'Weighing the risks of excessive participation in asynchronous online discussions against the benefits of robust participation', MERLOT Journal of Online Learning and Teaching, vol. 6, no. 1, pp. 55-61.

57. Yeung, A. S., Jin, P., \& Sweller, J. (1998) 'Cognitive load and learner expertise: Split-attention and redundancy effects in reading with explanatory notes', Contemporary Educational Psychology, vol. 23, pp. 1-21. doi: 10.1006/ceps.1997.0951

58. Yeung, A. S. (1999) 'Cognitive load and learner expertise: Splitattention and redundancy effects in reading comprehension tasks with vocabulary definitions', The Journal of Experimental Education, vol. 67, no. 3, pp. 197-217. doi: 10.1080/00220979909598353

59. Zydney, J. M., Warner, Z., \& Angelone, L. (2020) 'Learning through experience: Using design based research to redesign protocols for blended synchronous learning environments', Computers \& Education, vol. 143, p. 103678. doi: 10.1016/j.compedu.2019.103678 


\section{APPENDIX A}

\section{Example questionnaires}

\section{Structure-Processing}

What is the best combination durring the
lecture: Introduction to polymer science?

\section{Property-Processing}

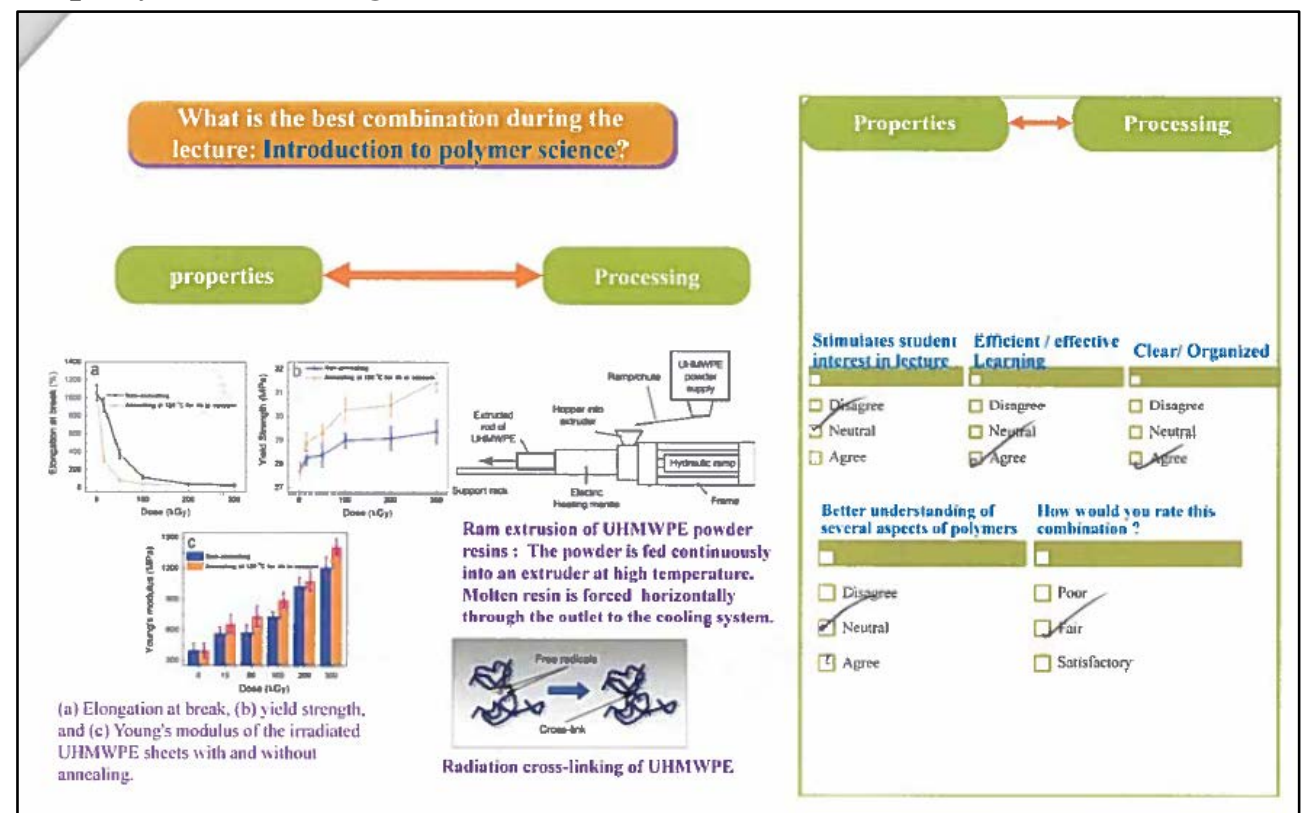




\section{Property-Characterization}

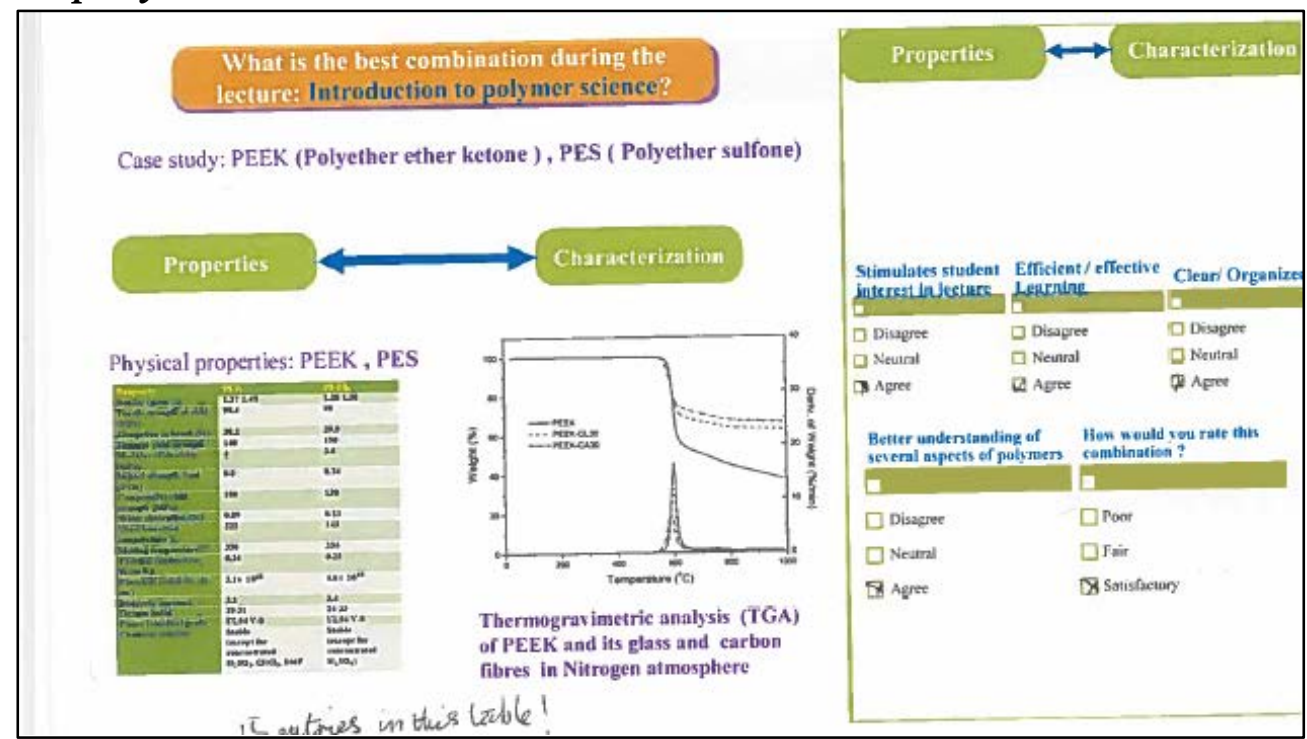

\section{Structure-Characterization}

\begin{tabular}{|l|l|l|l|} 
What is the best combination during the \\
lectures Introduction to polymer science?
\end{tabular}


July 2021 edition Vol.17, No.25

\section{Structure-Property}

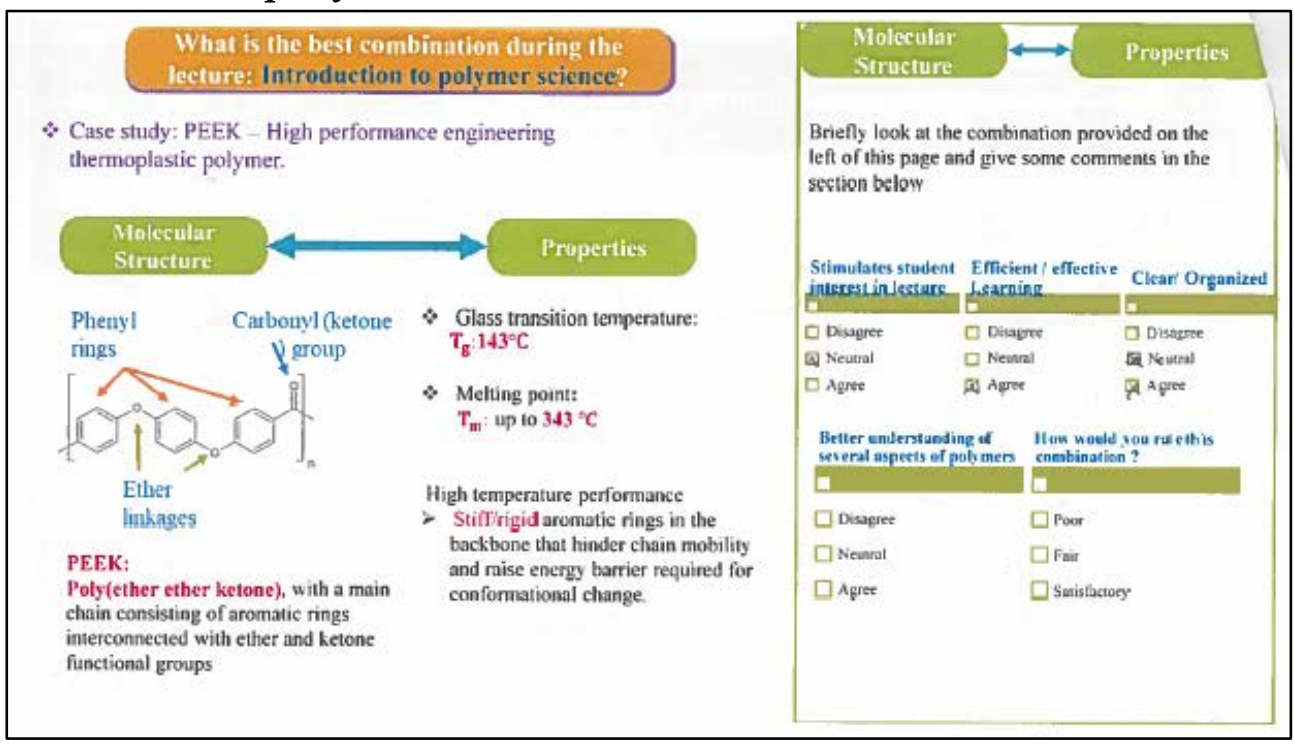

\section{Characterization - Processing}

$\begin{gathered}\text { What is the best combination during the } \\ \text { lecture: Introduction to poly mer science? }\end{gathered}$
C Case study: PEEK

